\title{
Digital pedagogy for safety: the construction site as a collaborative learning environment
}

\author{
Sarah Pink ${ }^{1 *}$, Helen Lingard ${ }^{2}$ and James Harley ${ }^{2}$
}

\author{
* Correspondence: \\ Sarah.pink@rmit.edu.au \\ ${ }^{1}$ School of Media and \\ Communication, RMIT University, \\ Melbourne, Australia \\ Full list of author information is \\ available at the end of the article
}

\begin{abstract}
In this article we examine the introduction of digital video pedagogy into dynamic workplaces with fast-changing social and material environments, and discuss its potential to participate in producing forms of positive change. The discussion brings together two strands: we investigate workplace learning theoretically as it emerges as part of a digital material world; and we consider how we might re-think workplace learning through possibilities of digital technologies. We develop this discussion through the example of how digital video has been used to engender new ways of learning and knowing about safety in one of the most dangerous workplaces globally - the construction industry.

Keywords: Video pedagogy, Digital pedagogy, Digital materiality, Construction industry, Worker safety, Video ethnography, Digital ethnography
\end{abstract}

\section{Introduction}

Everyday worlds are increasingly characterized by new configurations of the digital and material, and the affordances this offers. Therefore novel possibilities for bringing digital video pedagogies into physical material workplaces that have not traditionally been ICT focused are opening up. In this article we argue that the introduction of digital video pedagogy into dynamic workplaces with fast-changing social and material environments, can (if carefully implemented) bring radical forms of positive change. This, we propose offers novel ways of conceptualising the possibilities of digital video as a mode of learning in emergent environments and knowledge contexts, as well as insights into how digital material workplaces might beneficially be constituted as safe working environments. We develop this discussion through the example of how digital video has been used to engender new ways of learning and knowing about safety in one of the most dangerous workplaces globally - the construction industry.

In recent articles about the use of digital video for improving safety in the construction industry we have developed two core arguments. The first focuses on the use of participatory video as an effective form of visual pedagogy for safety (Lingard et al. 2015). The second concerns how forms of worker creativity, knowing and improvisation can be acknowledged, made visible and nurtured through the use of digital video in the construction industry (Pink et al. forthcoming). We have also specifically

(C) 2016 The Author(s). Open Access This article is distributed under the terms of the Creative Commons Attribution 4.0 International License (http://creativecommons.org/licenses/by/4.0/), which permits unrestricted use, distribution, and reproduction in any medium, provided you give appropriate credit to the original author(s) and the source, provide a link to the Creative Commons license, and indicate if changes were made. 
situated these arguments and the developments they demonstrate in relation to a discussion of how the digital and material are co-configured in contemporary everyday life and working contexts. In this article we bring these points together and advance our argument further through a deeper examination of how a collaborative learning environment might be constituted in the context of the construction industry through the use of digital video. In doing so we draw on and show clips from our video ethnography research undertaken on Australian construction sites in 2015.

The discussion has two strands: to investigate workplace learning theoretically as it emerges as part of a digital material world; and consider how we might re-think workplace learning through the digital for contexts like construction industry. That is, in an industry with a lack of apprenticeships, a fragmented and continually changing workforce where subcontracting is common (Fellini et al. 2007; Trajkovski and Loosemore 2006), where many workers have relatively low literacy skills and where much learning and knowing about workplace tasks is tacit (Senaratne and Sexton 2008; Laufer et al. 2008), learned on the job, and infrequently spoken about, and where the workplace itself is in a continuous and rapid process of social, material and technological change.

In what follows we first outline the context of the construction industry, the problem of safety and its regulation in the industry, and current research insights into the ways of knowing and learning associated with this particular workplace. We then bring together and configure a set of theoretical tools for considering the construction site's emergence as a collaborative learning environment, through a focus on notions of digital materiality, situated learning and video pedagogy. Before next discussing examples from the digital video project that we take as our example here, we outline our video ethnography research methods and process and its relationship to how we use video in this article. We then draw from our research materials to show how our video research has revealed a series of key possibilities that emerge from the use of digital video, and the implications that these collectively have for how learning and knowing through non-written text forms has for the industry. Indeed, we argue that this has implications that go far beyond learning about safety. Instead because safety is embedded in the work itself, our findings have impact across a range of other fields - from training to worker empowerment.

\section{The context: knowing and safety in the construction industry}

While use of digital technologies in workplace learning is not a new research topic, the question of a pedagogy for safety in the construction industry is relatively unknown in education studies/pedagogy research. Yet there is good reason for scholars from outside the disciplines that have traditionally focused on workplace safety, to bring new theoretical and practical expertise to tackling the perennial problems that persist in this field: as we summarise elsewhere 'The construction industry is one of the most dangerous places that it is possible to work. For instance construction "accounts for only about $5 \%$ of the employees in Britain [yet] it accounts for $27 \%$ of fatal injuries to employees and $10 \%$ of reported major injuries" with "39 fatal injuries to workers" in 2012-2013 (HSE 2014a), generating significant programmes of OSH initiatives, research, and guidance (e.g., HSE, 2003a, 2003b, 2014b)' (Pink et al. 2014a: 336). In Australia where the example we discuss in this article is located, 'from 2007-08 to 2011-12, 211 construction workers died from work-related injuries' representing 'nearly twice the national 
rate' with an average of 39 claims daily from employees requiring 'one or more weeks off work because of work-related injury or disease' (http://www.safeworkaustralia.gov.au/)' (Pink et al. forthcoming). Therefore, in the construction industry new thinking in relation to how to achieve safety is needed, and a digital video pedagogy offers some strong benefits (Lingard et al. 2015).

However the construction industry also provides an ideal example for our discussion, not simply because it is an industry where these challenges need to be addressed, but because construction sites are workplaces where it is possible as a researcher to experience and observe an everyday working environment in progress, where workers confront and evaluate new situations that continually emerge in a visible way. Ironically, while construction work has typically been researched qualitatively using interviewbased techniques, workers experience and know it predominantly in ways that are nonverbal. Thus it can also be treated as a living lab, from which there is much to learn about how digital video pedagogies can be usefully developed. We discuss this in more depth below with reference to our research methods.

The existing literature about safety in the construction industry suggests two types of knowledge about safety at play in this context: formal written knowledge that is used to constitute documented regulatory frameworks for occupational safety and health $(\mathrm{OSH})$; and informal ways of knowing whereby learning is an ongoing process. However on construction sites much workplace learning is tacit, embodied, infrequently spoken about explicitly, and undocumented in the industry's training and safety materials. The latter can involve a particular way of performing a task in a way that, as one of our participants put it, 'feels right'.

$\mathrm{OSH}$ legislation (in Australia and internationally) requires employers to consult workers when making decisions about how to best address safety hazards associated with the tasks they perform. Specifically, employers have a responsibility to consult workers about ways of working that could impact their health and safety and, conversely, workers' have the right to be consulted. Despite these requirements, conventional ways of managing workers, adopt a "top down" approach (Hale and Borys 2013) in which workers' behaviour is seen as something to be controlled through the enforcement of rigid rules which are usually developed by managers and technical specialists with minimal worker input (Sherratt et al. 2013; Lingard et al. 2015). In this approach, consultation is rarely meaningful (Ayers et al. 2013) and informal ways of knowing about health and safety are subjugated in favour of technical expertise. Typical approaches to safety training implemented in the construction industry involve a one-way flow of knowledge from a technical expert to the audience. This approach is ineffective because it is ill-suited to adult learning in which participants have a good understanding of their environment and possess valuable knowledge about working safely (Wilkins 2011). Alternative, participatory approaches to safety training have been found to be more effective in the construction context (Burke et al. 2006).

While workers' own ways of knowing are often highly effective in the prevention of fatal or significant accidents at work, they are not necessarily always complete or fully informed because they are based on a limited set of situation-specific experiences and also because the industry is one where aspects of the knowledge needed about a particular task or environment cannot necessarily be learned or shared through such forms of embodied learning. Thus, as we show through examples discussed below, knowledge 
may need to be garnered from different workers, technical specialists, managers and documents. Ironically however, while construction industry safety regulations and procedures are usually provided in written text form, many workers have low levels of literacy, making reading such texts an onerous, time consuming if not impossible task to undertake (Australian Bureau of Statistics 2013). While safety videos are often shown as part of compulsory site induction processes, these tend to be abstract, not site specific, and difficult for workers to relate to (or even understand if they are migrant workers with low local language skills) (Trajkovski and Loosemore 2006; Tutt et al. 2013). Moreover, as we have noted above, as a working environment, construction sites are complex and dynamic, with people and things moving rapidly through them and as such they are ongoing and visibly changing social and material configurations. This means that they can be regarded as extreme examples of contexts for learning as described by Goodyear and Carvalho in writing that "learning activity takes places in complex, messy dynamic situations in which interactions between elements produce conditions that are more or less supportive of learning' (2013: 51).

The existing literature recognizes these issues, yet to date practical solutions to them have been limited. Recent work has emphasised how 'In the case of workers' safety, ..., there is a notable misfit and gulf between a paper-based predictive and preventative, regulatory safety culture, and the ways that workers know (about) and perform safety on an everyday basis (Hale and Borys 2013; Lingard et al. 2015)' (Pink et al. forthcoming). Indeed it is precisely because construction sites are not wholly predictable environments that we argue that digital, visual and mobile technologies open up the possibility for more radical and critical pedagogies towards worker safety.

\section{Refiguring the learning environment: digital materiality, situated learning and visual pedagogy}

In a contemporary context where mobile media and technologies are increasingly ubiquitous in everyday life, making multiple digital platforms accessible from most material workplaces through broadband networks or wifi, being at work can be understood as participating in a digital material environment. In this understanding we do not necessarily see the construction site as a formerly material environment that now connects with the digital. Instead we are seeking to go beyond such binary renderings of what is digital and what is material. As such we conceptualise the construction site as a workplace where digital and material elements can potentially co-evolve in relation to each other, as part of the same or shared environment (see also Pink et al. forthcoming). We use the term digital materiality to refer to a situation where 'the digital, the material and design are not specific and separate things, but are rather more porous elements of processes of research, design and intervention' (Pink, Ardevol and Lanzeni 2016b).

Following this definition, therefore our emphasis is on understanding how digital technologies (e.g. smart phones and tablets) and digital platforms and media content (e.g. digital video platforms and content mainly, but also sms) and the material environment of the construction site become entangled as workers navigate an everyday working life which involves their embodied and sensory engagements with the digital and the material in relation to each other. Indeed in the example we discuss below, they might be said to work in an environment where digital technologies form part of the materiality of the workplace, and where the materiality and embodied tasks that are 
carried out in the workplace are inextricable from their relationship with digital media. Understanding the construction site as such - as a potentially digital material environment - therefore has implications for how we might also understand it as a learning environment. As Goodyear and Carvalho point out the term learning environment 'is widely used but rarely explained in writing about learning technologies' (Goodyear and Carvalho 2013: 50). However we suggest that the concept of digital materiality aids such a conceptualization, and offers us a new rendering of the environments in which we might understand situated learning (Lave and Wenger 1991) as being played out.

In the context of discussions about digital pedagogy, Goodyear and Carvalho insist 'person and environment are mutually entailed' (2013: 50), that is they are interdependent concepts. Likewise Fors, Bäckström and Pink have suggested 'focusing on the ways in which "situated learning" is embedded both in specific environments and in the embodied activities of learners'. This, they suggest offers a practical route through which as researchers we might focus on how the sensory perception of the environment is part of the learning process, thus inviting us to understand learning not as embodied but as emplaced' (Fors et al. 2013: 182). As such, they suggest a focus on the mindbody-environment relationship (which Howes (2005) uses to describe emplacement).

Bringing the concept of digital materiality to the discussion of what such a learning environment that includes digital technologies might be is consistent with a definition of digital materiality as being concerned with the relationality of things, rather than their separation. Here, 'Rather than starting with an a priori definition about what is digital and what is material, we prefer to understand digital materiality as a process, and as emergent, not as an end product or finished object. In doing so we break down the boundaries that are assumed when questions are asked about what is digital and what is not' (Pink, Ardevol and Lanzeni 2016b: 10). If the environments in which we live can be thought of as inextricably digital in such a way that we do not separate out what is digital from what is material then we can reconsider contemporary digital learning environments in the same way. Indeed, recent thinking has emphasized how our embodied experiences of technologies are implicated precisely with the environments in which we dwell and learn. Fors builds on existing work (Green 1998; Ihde 2002; Dall'Alba and Barnacle 2005; Richardson 2007; Moores 2012) to point out: 'new media-based orders of learning call for a deeper understanding of the whole body's association in and with digital technologies beyond more logo-centric, print-based, and ocular-centric ideas of learning'. Acknowledging Ellsworth's (2005) critical discussions about how language, the rational and predictive have been priviledged over the sensory, affective and playful in learning research and practice, she call for further emphasis on the embodied, sensory and unspoken elements of learning (Fors 2013: 277).

These arguments have resonance with those emerging in critical construction industry safety research. For instance, elsewhere we have called for the use of participatory video techniques for OSH improvement in the construction industry as a response to the rather similar constraints presented by the increasing proceduralisation of $\mathrm{OSH}$, in a context when 'Fucks and Dien (2013, p. 32) warn that the over-bureaucratization of $\mathrm{H} \& \mathrm{~S}$ can result in the reduction of people to mere 'robots' for whom an unthinking compliance with rules takes precedence over working safely' Lingard et al. 2015: 1). There is also a critical strand in the literature about safety in the construction industry 
that focuses on the importance of embodied knowing (e.g. (e.g. Strati 2003; Gherardi and Nicolini 2002; Marchand 2003, 2007). Taking this further here, we suggest that the construction site might be conceptualised as and indeed emerge in a practical sense as a digital material learning environment for sensory and emplaced situated learning. This is particularly pertinent when we account for the resonance between the particular ways that digital video and mobile technologies are being used within the new safety pedagogy discussed below in this article.

There are also characteristics of the ways digital media are used in the example that we discuss that make it particularly interesting as a digital material learning environment. First the use of digital video to engage with and record sensory, embodied and unspoken ways of experiencing, knowing and learning is particularly suitable to the move away from a words-based regulatory culture of safety (see Lingard et al. 2015, Pink et al. submitted). Moreover, Kukulska-Hulme and Traxler argue that 'mobile technologies are highly suited to learning that has variously been described as informal, opportunistic, spontaneous' (2013: 250) - as it indeed does need to be in the conditions of the continually changing environment and composition of the construction sites. Kukulska-Hulme and Traxler (2013: 250) note that such learning is 'also disruptive'; as we elaborate below in the context of the construction industry mobile learning can be seen as disruptive as a form of worker empowerment.

In the Australian context, where we undertook our research (as well as globally), we suggest that such an approach is timely since the uptake of mobile and smart technologies is on the increase. In 2014, $70 \%$ of Australians accessed the Internet using mobile devices, and there was $97 \%$ growth in the amount of mobile data downloaded (ACMA 2015). And 'At December 2014, 2.1 million adult Australians, or $12 \%$ of the adult population, were exclusively mobile. These are adult Australians who do not have either a fixed-line telephone or fixed internet connection, instead using mobile devices for voice communications, messaging and internet access at home' (ACMA 2015) - which was an increase from $10 \%$ in the preceding 12 months. Mobile technologies are increasingly part of people's everyday lives, including workplaces like construction sites and their presence is also suggestive for how we might reconceptualize the construction site a learning environment. Existing research about the use of mobile and smart technologies in the construction industry is not extensive, but shows that they are used for a variety of formal and informal communications purposes (Brown and Perry 2000; Pink et al. 2014b; Lingard et al. 2015; Chen, and Kamara 2011; Pink et al. submitted). We need to acknowledge that such workplaces need to be understood as digital material environments and therefore hold the potential to become digital learning environments. It is to an example of this that we turn shortly in this article. First, in the next section we outline our research partnership, methods and process.

\section{Digital video as research and pedagogy}

The research discussed in this article was developed as a collaboration which brought together the expertise and interests of researchers from the Centre for Construction Work Health and Safety Research (Lingard and Harley), and the Digital Ethnography Research Centre at RMIT University, and the company CodeSafe Solutions, which provides a suite of digitally based services oriented towards workers 
safety (CodeSafe Clip A). Please click the following link to view the video clip:

CodeSafe Clip A: https://www.youtube.com/watch?v=_nZPd1SKSNg

CodeSafe's own videos about their business describe the company and its aims from both the perspective of David (CodeSafe Clip B), the founder and its benefits for other companies (CodeSafe Clip C). Please click the following link to view the video clip:

CodeSafe Clip B: https://www.youtube.com/watch?v=_Ceps7BAf4k

CodeSafe Clip C: https://www.youtube.com/watch?v=Kuy3P7RsyyU.

We recommend that readers view these videos in order to gain a sense of the corporate elements of the digital context we discuss here; these existing documents demonstrate significant elements of the company's approach and the attachment David and his team have to it. Personal experience and engagement underpin their projects, both for them and for the workers involved. Our video ethnography research, filmed collaboratively with CodeSafe, also captured this sentiment. For example, as in Video Ethnography Clip A, where Milko who has worked in the industry for many years recounts what the CodeSafe process and people have meant to him. Please click the following link to view the video clip:

Video Ethnography Clip A: https://www.youtube.com/watch?v=dFXOgrbCAUI

Indeed, at this point in the process, Jacqui who collaborates in CodeSafe's video production and was off-screen with James during the interview became emotional. They then hugged, showing the engagement and relationship built up through the collaborative digital videomaking process. This was a core element of the environment in which the fieldwork was undertaken, in that the CodeSafe team engaged workers in their projects in ways that made them feel they were valued contributors. Moreover the whole project was underpinned by a conviction, based on our earlier research with the company, that their work took new steps towards safety which had been developed intuitively by David, which, as we show in this article (see also Lingard et al. 2015; Pink et al. forthcoming), can also be explained academically.

Our aim was to use video-based research methods in combination with interviewing and ethnographic field notes to study CodeSafe's methods of collaboratively producing videos of safe working procedures, and then disseminating them through an online platform. The research was undertaken in construction sites in Australia in 2015 and produced, in collaboration with CodeSafe, five interviews and seven and a half hours of video footage across five sites and procedures. Using video as a research method was important in this project for a number of reasons. Video ethnography is now well established as a means through which to bring to the fore tacit, normally unspoken, sensory and emotional elements of human activity and experience (Pink 2013, and see www.energyanddigitalliving.com). Video has usefully been used in interdisciplinary team research (Leder, Mackley and Pink 2013) in order to communicate about these aspects of experience with colleagues, and in ethnographic filmmaking to reach wider audiences through empathetic means (MacDougall 1998, 2005). In this project, these affordances of video have three forms of relevance. Firstly, our research was concerned with the capacity of the CodeSafe system to communicate the unspoken and 
experiential aspects of safety as a digital video pedagogy (Lingard et al. 2015) within the construction site as a digital material learning environment. Secondly, we worked across an interdisciplinary, and academic-industry connected team, in order to use the videos to engender shared empathetic understandings of the experiences of both the participants in the video (who included the CodeSafe industry partners) and the fieldworker (Harley). Thirdly, a collaboratively edited documentary video will be used to communicate our findings and argument in industry contexts more broadly.

We collectively viewed the video recordings to develop a themed analysis of the key findings as they emerged from the materials. This involved intensive individual viewing and note taking, and collective and consultative viewing in which three areas of expertise were brought together: construction and OSH (Lingard); video and digital ethnographic practice and construction industry and safety ethnographies (Pink); and cultural studies and ICT-enabled collaboration methods along with the experience of undertaking the fieldwork (Harley).

In the following sections we present a series of our key findings to demonstrate how the elements that form part of the configuration of the construction sites as a potential digital learning environment emerged.

\section{Making a collaborative learning environment}

In this section we focus on how CodeSafe's process of making and disseminating videos involves the constitution of a collaborative learning environment focused around the use of digital and visual technologies. We structure our discussion around the narrative of the making and use of videos as they were played out in our video ethnography, and as they emerged from our analytical sessions with the materials.

During our research on construction sites, David the founder and CEO of CodeSafe, workers, safety managers and video makers collaborated to plan, script and film insulation work and scaffolding as shown in Video Ethnography Clips B and C. Please click the following link to view the video clip:

Video Ethnography Clip B: https://www.youtube.com/watch?v=TGPIUpRP23w

Video Ethnography Clip C: https://www.youtube.com/watch?v=Q_dCiBfHV_M

As we viewed the videos we came to understand all of these aspects of the process as part of the making of a digital material environment, from which new forms of learning were continually emerging. That is, as the shared objective was to make digital videos, which would be posted online, the collaborative learning process began. These collaborations were not rapid, but emerged through planning discussions that panned out over time as the workers and CodeSafe staff contemplated the material and sensory elements of the environment and task, in the actual location where it would be video recorded. This can include discussions of a range of aspects of the existing building and how it can be physically navigated safely, the weather and the equipment to be used (see Video Ethnography Clip C). During these discussions questions of safety were debated, moments of learning and awareness emerged, and were connected with the question of how to video record a safe process. The following video example of the process of planning 
demonstrates this and aims give readers/viewers a sense of how this learning environment becomes constituted during the planning stage. As is evident, workers and the CodeSafe team were learning from each other, and drawing in relevant experiences and knowing from other sources to form a collective interpretation that they would later demonstrate in the videos they made. Please click the following link to view the video clip:

Video Ethnography Clip D: https://www.youtube.com/watch?v=i5bKd2zBz8E

In Video Ethnography Clip D we see how learning in a particular environment is important for the beginning of any task, as this involved accounting for the specificities of that environment in relation to a series of generic issues that were pulled together by the team, and sometimes reveal gaps in knowing that show the importance of the collaborative process in the planning stage.

The scripting processes were equally collaborative. As we see in Video Ethnography Clip E, digital learning was embedded in how scripting was conceptualized, with workers showing a clear vision of who their audience would be. The detail of the video recorded discussion is significant here, since the worker changed terminology to make it accessible for the audience and in ways that directly contested the conventional formats in which safety regulations and procedures are presented. The spoken and visual/embodied/ emplaced elements of the videos produced offer alternative modes of communication to workers, beyond the printed word. They account empathetically for the situatedness of the potential viewer, and communicate verbally and visually in narratives that are relevant. Significantly they are produced in such a way that directly contests the authority of conventional forms of textual communication and representation in the industry towards embodied, emplaced sensory and affective accounts of how safety is performed and why it matters. Please click the following link to view the video clip:

Video Ethnography Clip E: https://www.youtube.com/watch?v=JppG1d3BZ74

The learning process continued through the actual video recording process itself. Here the collaboration brought together a series of different forms of expertise, including David drawing from his professional experience in construction, and making the CodeSafe videos, and the workers and safety managers who became involved. This is significant to keep in mind because it brings to the fore the role of actually enacting a task in the production of new ways of knowing that emerge through what is learned in its performance (and in this case collective learning). As such we can understand these videos as recording not simply a task as a static and fixed procedure, but as being a representation of a moment in a continuous process of learning in progress as it emerges in a particular environment. The videos in this sense are not final texts that contain knowledge that needs to be transmitted, but are documents that emerge within a process of worker learning that others can refer to as part of further processes. This understanding acknowledges the limits of written texts as fixed statements and enables us to account for the situatedness of knowing and learning as emerging from particular environments and configurations of things and processes. The CodeSafe videos are made in ways that acknowledge this contexuality and situatedness, and are always used in ways that are similarly situated in different environments. This understanding however also enables us to shift the idea of 
what a CodeSafe video is, and that it not as a video of a procedure that can be abstracted to being the procedure. Rather it is an example of how a procedure was recorded when played out safely in a particular set of circumstances, which will be similar to other future situations. However when viewed again in a new environment it is already part of that new digital material environment itself. Following the theoretical discussion outlined above, it is integrated into the digital materiality of that everyday world.

The workers discussed with us viewing the videos in the everyday world of the construction site, and offered what are perhaps some of the obvious benefits given our discussion above. For example, one worker said: "you see people doing it, see what has to be done or [what] you shouldn't be doing so it's better than reading." Another commented: "I think it's a better way than verbally or writtenly trying to tell someone safety methods...I think a visual is definitely the best way to get your point across." Other workers commented that workers would be more likely to engage with and understand the content of visual procedures than written procedures. In describing the potential benefits associated with visual communication the workers indicated that, while written communication can tell people what is required, visual communication shows them how to perform the work safely. One commented:

"It's a lot easier to show someone what we're trying to say. We could just to sit here and verbally speak about it but if you put your verbal words into a video, people are going to sit back and go 'now I know what he's actually trying to say."

He continued:

"see how I can talk about stuff, this and that, and in your own head you'd get your own visual perception of what's meant to be going on, rather than someone actually going there, showing you, going 'okay look, I'm going to put this in between this and this and if I was to shoot a pin there'...so yeah, I reckon it's definitely a better way of getting your point across. Visually showing someone."

The difference between knowing what (or what not) to do and knowing how to do it was reiterated by another worker who commented: "I just think it's a lot easier to visually show that you're not to shoot a pin into this area, as to 500 words or something to describe the same thing."

During our research process we encountered various instances of workers not knowing, or not having learned information that they identified as being crucial to safe working, but that could be simply embedded in a video. However there was an added element to this, which again brings to the fore the specific nature of digital video and the impact on learning that the constitution of a digital material environment might enable. While some of the CodeSafe videos are accessible only through the specific platform that is used by the company that has commissioned their work, others are freely available online. Examples of some of the methods that CodeSafe has video recorded in collaboration with the Master Builders Association in Australia, can be viewed on the Association's web site, here http://www.mbav.com.au/vplink.aspx?ID=8998 (accessed $23^{\text {rd }}$ November 2015). As it states there, 'The procedures demonstrated in these guidelines were developed by undertaking an appraisal of safe systems of work for each topic, consulting with workers who regularly undertake these tasks and refining these processes for demonstration'. However 
it is not only such associations who are involved in sharing videos, but rather, as one participant described, such systems also enable workers to share videos amongst themselves, by sending an sms link to a colleague who has asked how to perform a task. Significantly however, worker sharing begins to constitute more than their empowerment through knowledge sharing in the video making process. Rather the possibility to share videos in a context where sharing written regulatory documents is not feasible, enables workers to possess and adhere to authoritative accounts of how to undertake a task safely in contexts where they might have been asked by a manager to work in a less safe way as discussed in Video Ethnography Clip F. Please click the following link to view the video clip:

Video Ethnography Clip F: https://www.youtube.com/watch?v=5iU2zrdqDlo

\section{The implications of a digital-material pedagogy}

Above we have outlined how a collaborative digital-material learning environment has been constituted through one example of an innovative initiative in the construction industry - an industry where safety presents a great challenge, where conventional textbased methods of learning about safety tend to be difficult to effect, in part because embodied knowing and learning tend to take precedence. The example we have described can be seen as a system that has been developed using digital technologies to build on these existing ways of knowing and learning and to engage them for a safety pedagogy. However, we suggest that the implications for the industry as well as the wider implications of implementing a radical shift in learning go further. In this section we discuss how the characteristics of a digital-material pedagogy create new possibilities in the construction industry, which in turn demonstrate the utility of attending to digital materiality in other learning contexts beyond this.

As Jandrić and Boras remind us 'human learning is always political' (2015: 4), and this point is particularly pertinent in relation to the field of digital learning, and its relationship to what has been called 'digital politics' (Postill 2012). They also note that 'the contemporary field of networked learning has been firmly interlocked with the tradition of radical education and critical theory' (Jandric and Boras 2015: 4). For instance, 'Critical Digital Pedagogy' as defined by Stommel, has a number of characteristics that make it stand in contrast to the ways that regulatory frameworks are conventionally disseminated in the construction industry. A critical digital pedagogy: 'centers its practice on community and collaboration'; 'must remain open to diverse, international voices, and thus requires invention to reimagine the ways that communication and collaboration happen across cultural and political boundaries'; 'will not, cannot, be defined by a single voice but must gather together a cacophony of voices'; and 'must have use and application outside traditional institutions of education' (Stommel 2014, no page numbers, emphasis in the original). The collective and community building elements of the example we have discussed here certainly coincide with these aspects of a digital pedagogy. As we have shown, the possibilities associated with using digital video for learning can present a radical shift in that workers themselves have greater scope to contest unsafe practices. As noted above, worker safety has commonly been presented in the industry as a matter of worker compliance to regulatory frameworks, and top down enforcement has been seen as a solution. However, as our video ethnographies have shown, workers themselves have a strong commitment to safety - '... getting 
home to your family at night' (see Video Ethnography Clip F) which is demonstrated in their participation in the CodeSafe video making process, and in the possibility of worker sharing and dissemination of the videos. It is here where we see workers themselves as enabled to contest unsafe practices, and creating ways for safety to be better communicated and learned in the industry.

However, as we have also shown, the emphasis in understanding how this is effective needs to go beyond the digital and is more beneficially understood as happening as part of the relationality of the digital-material. Therefore, where Stommel argues that A Critical Digital Pedagogy demands that open and networked educational environments must not be merely repositories of content. They must be platforms for engaging students and teachers as full agents of their own learning' (2014, no page numbers), we would extend this to argue that a critical digital pedagogy can never be isolated from the digital materiality through which it is shaped and experienced. This is because experientially, for those who teach or co-learn, such platforms are always part of digitalmaterial configurations.

A similar argument may be made in relation to another common issue in the industry that has been drawn out in our analysis. Often safety is not integrated into everyday workplace tasks (or conversations about the way these should be performed) but tends rather to be located in inaccessible text-based documents. Conversely in the example discussed in this article, safety has become part of the process of developing and demonstrating the tasks on video. Here learning about safety becomes incorporated in learning about performing a task, as part of a digital-material environment. As safety becomes situated as part of this ongoingly evolving interface between digital, material and performed (and felt) tasks, as well as everyday smart phone practices such as sending a video or link via sms, there are possibilities for it to become part of rather than separate from the task.

In an industry where literacy levels are low, where migrant workers might have little local language knowledge, and where much knowing is embodied rather than verbal, training and learning need to be re-thought beyond written text-based materials. This coupled with the ubiquity of digital and mobile media in everyday life, and the skills that workers have in association with their media use offers an ideal opportunity to develop alternative modes of workplace learning. For the workers who participated in our project a lack of apprenticeship opportunities in their particular area of work also meant one-to-one workplace learning, through shared work activity had become less accessible to new workers. Indeed, the insulation installation tasks we focused on in this article are often undertaken by relatively unskilled workers. The development of digital pedagogies based on the communication of experiential knowing through digital video has the potential to enable the growth of digitally based learning communities in the industry. If this can be harnessed it may not offer the same opportunities for learning as would an apprenticeship model, but will offer less experienced workers alternative ways in which to draw on what is otherwise an invisible, intangible and inaccessible resource of embodied knowing, distributed across the bodies of workers in divergent locations.

\section{Conclusion}

In this example, the collective/collaborative, sensory/embodied/experiential/, digitalmaterial, are brought together to create a learning environment where safety and the 
task itself are integrated and where literacy is not a pre-requisite for learning. This creates a context that acknowledges how learning happens precisely at this interface, that learning is ongoing, relational and situated. To end, we return to a theory of digital materiality to argue that when added to existing debates about the nature of digital and visual pedagogies, this framework offers a way in which to conceptualise what have previously been loosely thought of as digital learning environments, in a way that more fully connects them to the situatedness of learning as emplaced. That is, to understand learning as inseparable from our embodied and sensory relationships to the digital materiality of the worlds we inhabit.

The engagements with the material construction site that the participants in this research project demonstrated cannot be seen as involving the material as opposed to the digital. Once a task has been videoed, edited and uploaded, the activity of viewing it and using it to inform work practices becomes part of the way that the construction site itself is constituted as digital material environment. This starts from the very moment that the workers and the CodeSafe team begin to plan how they will perform tasks that bring together the digital and material as part of the same environment.

Thus while our discussions of a digital pedagogy have made significant points in suggesting how radical shifts in approaches to and practices of learning might occur through the use of digital media, a further theoretical step is needed. This step entails understanding learning that involves the use of digital technologies and media not as a digital pedagogy, but as a digital material pedagogy. Such a perspective is particularly helpful when contemplating learning in unpredictable and dangerous environments, like construction or mining, as well as other industries where safety is a key concern for a range of reasons, such as the automotive industry, road safety generally and more.

\section{Acknowledgments}

The research discussed in this article was undertaken as part of the project "Using digital and mobile technology to improve construction health and safety". We thank all the participants who agreed to collaborate with us in this project. The research was generously funded by the SPUR initiative in the College of Design and Social Context at RMIT University, and developed in partnership with CodeSafe solutions, where we particularly acknowledge David Broadhurst, Jacqui Broadhurst and Andrew Gorrie for their work with us. This project was approved by RMIT University's Human Research Ethics Committee, reference number: 0000019065-10-14. We declare that there was no conflict of interest involved in our undertaking this research.

\section{Authors' contributions}

All authors were involved in the research design, bringing their particular areas of expertise to the research and analysis. Pink led the drafting of the article which was co-written with Lingard and Harley. All authors read and approved the final manuscript

Competing interests

The authors declare that they have no competing interests.

\footnotetext{
Author details

${ }^{1}$ School of Media and Communication, RMIT University, Melbourne, Australia. ${ }^{2}$ School of Property, Construction and Project Management, RMIT University, Melbourne, Australia.
}

Received: 19 January 2016 Accepted: 28 May 2016

Published online: 02 August 2016

References

ACMA (2015) Australians get Mobile., http://www.acma.gov.au/theACMA/engage-blogs/engage-blogs/Researchsnapshots/Australians-get-mobile, accessed 22 Nov 2015

Australian Bureau of Statistics (2013) 4228.0 - Programme for the International Assessment of Adult Competencies, Australia, 2011-12, Canberra 
Ayers G, Culvenor J, Sillitoe J, Else D (2013) Meaningful and effective consultation and the construction industry of Victoria. Constr Manage Econ 31(6):542-67

Brown B, Perry M (2000) Why don't telephones have off switches? Understanding the use of everyday technologies: a research note. Interacting with Computers 12:623-634

Burke MJ, Sarpy SA, Smith-Crowe K, Chan-Serafin S, Salvador RO, Islam G (2006) Relative effectiveness of worker safety and health training methods. Am J Public Health 96(2):315-24

Chen Y, Kamara JM (2011) A framework for using mobile computing for information management on construction sites. Autom Constr 20(7):776-788

Dall'Alba G, Barnacle R (2005) Embodied knowing in online environments. Educ Philos Theory 37:719-744

Ellsworth E (2005) Places of learning. Routledge, New York

Fellini I, Ferro A, Fullin G (2007) Recruitment processes and labour mobility: the construction industry in Europe. Work Employ Soc 21(2):277-298

Fors V (2013) Teenagers' multisensory routes for learning in the museum: pedagogical affordances and constraints for dwelling in the museum. Sens Soc 8(3):268-289

Fors V, Backstrom A, Pink S (2013) Multisensory emplaced learning: resituating situated learning in a moving world. Mind Cult Act 20(2):170-183

Fucks, I. and Dien, Y. (2013) 'No rule, no use'? The effects of over-proceduralization, in Bieder, C. and Bourrier, M. (eds.) Trapping Safety into Rules: How Desirable or Avoidable is Proceduralization?, Ashgate, Farnham, pp. 27-39

Gherardi S, Nicolini D (2002) Learning the trade: a culture of safety in practice. Organization 9(2):191-223

Goodyear P, Carvalho L (2013) The analysis of complex learning environments. In: Beetham H, Sharpe R (eds) Rethinking pedagogy for a digital age: designing for 21st century learning, 2nd edn. Routledge, Oxford

Green B (1998) Teaching for difference: learning theory and postcritical pedagogy. In: Buckingham D (ed) Teaching popular culture: beyond radical pedagogy. University College London Press, London, pp 177-97

Hale A, Borys D (2013) Working to rule, or working safely? Part 1: a state of the art review. Saf Sci 55:207-221

Health and Safety Executive (HSE). (2003a). Causal factors in construction accidents (Research Report 156). Retrieved from http://www.hse.gov.uk/research/rrpdf/rr156.pdf

Health and Safety Executive (HSE). (2003b). Sample analysis of construction accidents reported to the HSE (Research Report 139). Retrieved from http://www.hse.gov.uk/research/rrpdf/rr139.pdf

Health and Safety Executive (HSE). (2014a). Construction industry. Retrieved from http://www.hse.gov.uk/STATISTICS/ industry/construction/index.htm

Health and Safety Executive (HSE). (2014b). Construction Division. Plan of work 2014/2015. Retrieved from http://www. hse.gov.uk/construction/work-plan-2014-15.pdf

Howes D (ed) (2005) Empire of the senses: the sensual culture reader. Berg, Oxford

Inde D (2002) Bodies in technology. University of Minnesota Press, Minneapolis

Jandric P, Boras D (2015) Introduction. In: Jandric P, Boras D (eds) Critical learning in digital networks. Springer, London

Khoury H, Chdid D, Oueis R, Elhajj I, Asmar D (2015) Infrastructureless approach for ubiquitous user location tracking in construction environments. Autom Constr 56:47-66

Kukulska-Hulme A, Traxler J (2013) Design principles for mobile learning. In: Beetham H, Sharpe R (eds) Rethinking pedagogy for a digital age: designing for 21st century learning, 2nd edn. Routledge, Oxford

Laufer A, Shapira A, Telem D (2008) Communicating in dynamic conditions: how do on-site construction project managers do it? J Manag Eng 24(2):75-86

Lave J, Wenger E (1991) Situated learning. Legitimate peripheral participation. Cambridge University Press, Cambridge

Leder Mackley, K. and S. Pink (2013) 'From Emplaced Knowing to Interdisciplinary Knowledge: Sensory Ethnography in Energy Research' for Senses and Society, 8(3):335-353

Lingard H, Pink S, Harley J, Edirisinghe R (2015) Looking and learning: using participatory video to improve health and safety in the construction industry. Constr Manage Econ. doi:10.1080/01446193.2015.1102301

MacDougall D (1998) Transcultural cinema. Princeton University Press, Princeton

MacDougall D (2005) The Corporeal Image: film, ethnography, and the senses. Princeton University Press, Princeton

Marchand T (2003) A possible explanation for the lack of explanation: or, "why the master builder can't explain what he knows": introducing the information atomism against a "definitional" definition of concepts. In: Pottier J, Bicker A, Sillitoe P (eds) Negotiating local knowledge. Pluto, London

Marchand T (2007) Crafting knowledge: the role of "parsing and production" in the communication of skill-based knowledge among masons. In: Harris M (ed) Ways of knowing, new approaches in the anthropology of experience and learning. Berghahn, Oxford

Moores S (2012) Media, practice \& mobility. Palgrave Macmillan, Basingstoke

Pink S (2013) Doing visual ethnography. Sage, London

Pink S, Morgan J, Dainty A (2014a) Safety in movement: mobile workers, mobile media. Mobile Media Commun 2(3):335-351

Pink S, Morgan J, Dainty A (2014b) The Safe Hand: gels, water, gloves and the materiality of tactile knowing. J Mater Cult 19(4):425-442.

Pink S, Ardevol E, Lanzeni D (eds) (2016b) Digital materialities: design and anthropology. Bloomsbury, Oxford

Postill J (2012) Digital politics and political engagement. In: Horst H, Miller D (eds) Digital anthropology. Berg, Oxford

Richardson I (2007) Pocket technospaces: the bodily incorporation of mobile media. Continuum-J Media Cu 21(2):205-15

Senaratne S, Sexton M (2008) Managing construction project change: a knowledge management perspective. Constr Manage Econ 26(12):1303-1311

Sherratt F, Farrell P, Noble R (2013) UK construction site safety: discourses of enforcement and engagement. Constr Manage Econ 31(6):623-35

Stommel J (2014) 'Critical Digital Pedagogy: a Definition'., Hybrid Pedagogy, http://web.archive.org/web/ 20150325002121/http://www.hybridpedagogy.com/journal/critical-digital-pedagogy-definition/, accessed 22 Nov 2015 
Strati A (2003) Knowing in practice: aesthetic understanding and tacit knowledge. In: Nicolini D, Gherardi S, Yanow D (eds) Knowing in organisations. M.E. Sharpe Inc., New York

Trajkovski S, Loosemore M (2006) Safety implications of low-English proficiency among migrant construction site operatives. Int J Proj Manag 24(5):446-452

Tutt D, Pink S, Dainty AR, Gibb A (2013) Building networks to work: an ethnographic study of informal routes into the UK construction industry and pathways for migrant up-skilling. Constr Manage Econ 31(10):1025-1037

Wilkins JR (2011) Construction workers' perceptions of health and safety training programmes. Constr Manage Econ 29:1017-26

\section{Submit your manuscript to a SpringerOpen ${ }^{\circ}$ journal and benefit from:}

- Convenient online submission

- Rigorous peer review

- Immediate publication on acceptance

- Open access: articles freely available online

- High visibility within the field

- Retaining the copyright to your article

Submit your next manuscript at $>$ springeropen.com 